\title{
Genetic factors for lone atrial fibrillation
}

\author{
KIMIHIKO KATO ${ }^{1}$, MITSUTOSHI OGURI ${ }^{1}$, TAKESHI HIBINO ${ }^{1}$, KAZUHIRO YAJIMA ${ }^{1}$, \\ HITOSHI MATSUO ${ }^{2}$, TOMONORI SEGAWA ${ }^{2}$, SACHIRO WATANABE $^{2}$, HIDEMI YOSHIDA $^{3}$ \\ KEI SATOH ${ }^{3}$, YOSHINORI NOZAWA ${ }^{4}$, KIYOSHI YOKOI ${ }^{1}$ and YOSHIJI YAMADA ${ }^{5}$ \\ ${ }^{1}$ Department of Cardiovascular Medicine, Gifu Prefectural Tajimi Hospital, Tajimi; ${ }^{2}$ Department of Cardiology, Gifu \\ Prefectural Gifu Hospital, Gifu; ${ }^{3}$ Department of Vascular Biology, Institute of Brain Science, Hirosaki University \\ School of Medicine, Hirosaki, Aomori; ${ }^{4}$ Gifu International Institute of Biotechnology, Kakamigahara, Gifu; \\ ${ }^{5}$ Department of Human Functional Genomics, Life Science Research Center, Mie University, Tsu, Mie, Japan
}

Received October 16, 2006; Accepted December 28, 2006

\begin{abstract}
Atrial fibrillation (AF) may result from an electric conduction disturbance, increased hemodynamic stress, ischemia, inflammation, or remodeling in atria. Although genetic epidemiological studies have identified several genetic variants as risk factors for AF, the genetic determinants of this condition remain largely unknown. The purpose of the present study was to identify gene polymorphisms that confer susceptibility to lone AF. The study population comprised 1069 unrelated Japanese individuals, including 196 subjects with chronic lone AF and 873 controls. The genotypes for 40 polymorphisms of 32 candidate genes were determined by a method that combines the polymerase chain reaction and sequence-specific oligonucleotide probes with suspension array technology. Multivariable logistic regression analysis with adjustment for age, sex, body mass index, and the prevalence of smoking, hypertension, diabetes mellitus, and hypercholesterolemia as well as a stepwise forward selection procedure revealed that the $-1306 \mathrm{C} \rightarrow \mathrm{T}$ polymorphism of the matrix metalloproteinase 2 gene $(M M P 2)$ and the $-592 \mathrm{~A} \rightarrow \mathrm{C}$ polymorphism of the interleukin 10 gene (IL10) were significantly (false discovery rate of $<0.05$ ) associated with the prevalence of AF. The $T$ allele of the $M M P 2$ polymorphism and the $C$ allele of the $I L 10$ polymorphism were a risk factor for and protective factor against AF, respectively. Determination of the genotypes for these polymorphisms may thus prove informative for assessment of the genetic component of AF.
\end{abstract}

\section{Introduction}

Atrial fibrillation (AF) is the most common type of arrhythmia associated with an unfavorable outcome, particularly stroke.

Correspondence to: Dr Kimihiko Kato, Department of Cardiovascular Medicine, Gifu Prefectural Tajimi Hospital, 5-161 Maehata, Tajimi, Gifu 507-8522, Japan

E-mail: gogok@nifty.com

Key words: atrial fibrillation, arrhythmia, genetics, polymorphism, risk factor
The prevalence of AF in the US is $>2.2$ million (1). AF is responsible for $\sim 15$ to $20 \%$ of all strokes and is an independent risk factor for stroke, increasing the risk $\sim 5$-fold in the US. Given the importance of prevention of stroke, the identification of markers for AF risk is the key, both for risk prediction and for potential intervention to avert cardiogenic embolic stroke.

About $15-30 \%$ of AF patients have no underlying disease, with their condition being referred to as lone AF. Idiopathic forms of disease are traditionally not considered genetic in origin. In recent years, however, research attention has focused on the genetic aspects of AF (2) and several studies have shown that familial AF is more common than previously recognized (3-5). Of the 914 patients with AF, 36\% had lone $\mathrm{AF}$ and a family history of AF was present in $15 \%$ of these patients with lone AF (4). In addition, genetic linkage analysis and candidate gene association studies have implicated several loci (10q22-24, 6q14-16, and 5p13) $(3,6,7)$ and candidate genes, including KCNE1 (8), KCNE5 (9), and those for connexin 40 (10) and angiotensinogen (11), in predisposition to lone AF. The genetic determinants of lone AF, however, remain largely unknown.

We performed an association study for 40 polymorphisms of 32 candidate genes and lone AF in 1069 Japanese individuals. The purpose of the present study was to identify gene polymorphisms that confer susceptibility to lone AF and thereby to contribute to the personalized prevention of this condition.

\section{Materials and methods}

Study population. The subjects with AF comprised 196 consecutive unrelated Japanese individuals (153 men, 43 women) who visited the participating hospitals (Gifu Prefectural Tajimi Hospital, Gifu Prefectural Gifu Hospital, and Hirosaki University Hospital) between October 2002 and March 2005 and who were diagnosed with persistent AF in the absence of a history of structural heart disease, including congestive heart failure, coronary heart disease, or valvular heart disease such as mitral, aortic, tricuspid, or pulmonary stenosis or regurgitation. Structural heart disease was evaluated by measurement of biochemical markers, electrocardiography, examination of 
Table I. Primers, probes, and other PCR conditions for genotyping.

\begin{tabular}{|c|c|c|c|c|c|c|}
\hline Gene & Polymorphism & & Sense primer & \multicolumn{3}{|c|}{ Antisense primer } \\
\hline IL10 & $-592 \mathrm{~A} \rightarrow \mathrm{C}$ & \multicolumn{2}{|c|}{ gTggAAACATgTgCCTgAgAATC } & \multicolumn{3}{|c|}{ TAAATATCCTCAAAgTTCCCAAgC } \\
\hline IL10 & $-819 \mathrm{~T} \rightarrow \mathrm{C}$ & \multicolumn{2}{|c|}{ TgTgCTggAgATggTgTACAgT } & \multicolumn{3}{|c|}{ ATgCTAgTCAggTAgTgCTCAC } \\
\hline BCHE & $1615 \mathrm{G} \rightarrow \mathrm{A}(\mathrm{Ala539Thr})$ & \multicolumn{2}{|c|}{ TACAACTTATTCCATATTTTACAggA } & \multicolumn{3}{|c|}{ TgTAATTgTTCCAgCgATggAATC } \\
\hline CETP & $1061 \mathrm{~A} \rightarrow \mathrm{G}(\mathrm{Ile} 405 \mathrm{Val})$ & \multicolumn{2}{|c|}{ gCTCCAgggAggACTCACCA } & \multicolumn{3}{|c|}{ gATgCCCACAgCggTgATCAT } \\
\hline SLC26A8 & $\mathrm{A} \rightarrow \mathrm{G}(\mathrm{Ile} 639 \mathrm{Val})$ & \multicolumn{2}{|c|}{ CCAgATTCTTTACACAgAgCgAT } & \multicolumn{3}{|c|}{ gCAgTTTggCTTgTgTTCATgCT } \\
\hline$M M P 2$ & $-1306 \mathrm{C} \rightarrow \mathrm{T}$ & \multicolumn{2}{|c|}{ TCTgggCCATTgTCAATgTTCC } & \multicolumn{3}{|c|}{ gTgACTTCTgAgCTgAgACCTg } \\
\hline$T N F$ & $-238 \mathrm{G} \rightarrow \mathrm{A}$ & \multicolumn{2}{|c|}{ gTCCTACACACAAATCAgTCAgT } & \multicolumn{3}{|c|}{ gACACACAAgCATCAAggATACC } \\
\hline Gene & \multicolumn{2}{|l|}{ Probe 1} & \multicolumn{2}{|l|}{ Probe 2} & Annealing $\left({ }^{\circ} \mathrm{C}\right)$ & Cycles \\
\hline IL10 & \multicolumn{2}{|c|}{ CCCCgCCTgTACTgTAggAA } & \multicolumn{2}{|l|}{ ACCCCgCCTgTCCTgTAggA } & 60 & 50 \\
\hline IL10 & \multicolumn{2}{|c|}{ TACAggTgATgTAACATCTCTg } & \multicolumn{2}{|c|}{ gAggCACAgAgATATTACATCA } & 60 & 50 \\
\hline BCHE & \multicolumn{2}{|c|}{ CACTCCCATTCTgCTTCATCA } & \multicolumn{2}{|c|}{ САCТCССАТTCTgTTTCATCAAT } & 60 & 50 \\
\hline CETP & \multicolumn{2}{|c|}{ AgCTCCgAgTCCATCCAgAg } & \multicolumn{2}{|l|}{ ggAAgCTCTggACggACTCg } & 60 & 50 \\
\hline SLC26A8 & \multicolumn{2}{|c|}{ AAgCATCCTCCATTAACCTg } & \multicolumn{2}{|c|}{ TgAATCAggTTAACggAggATg } & 60 & 50 \\
\hline$M M P 2$ & \multicolumn{2}{|c|}{ САCССАgCАСТССАССТСТ } & \multicolumn{2}{|c|}{ AgAgCTAAAgAggTAgAgTgC } & 60 & 50 \\
\hline$T N F$ & \multicolumn{2}{|c|}{ СТCCCTgCTCCgATTCCgT } & \multicolumn{2}{|c|}{ CCCTCggAATCAgAgCAgg } & 60 & 50 \\
\hline
\end{tabular}

chest X-rays, echocardiography, radioisotope analysis, coronary angiography, and left ventriculography. Patients with hyperthyroidism, chronic lung disease, or excessive alcohol intake (>100 $\mathrm{g}$ of pure ethanol per day) were also excluded from the study.

Control subjects comprised 873 individuals (302 men, 571 women) who visited the participating hospitals for an annual health checkup and who had no history of AF or other significant supraventricular or ventricular arrhythmias or of taking antiarrhythmics.

The study protocol complied with the Declaration of Helsinki and was approved by the Committees on the Ethics of Human Research of Gifu Prefectural Tajimi Hospital, Gifu Prefectural Gifu Hospital, Hirosaki University School of Medicine, and Mie University School of Medicine. Written informed consent was obtained from each participant.

Selection of polymorphisms. With the use of public databases, we selected 32 candidate genes that have been characterized and were suggested to be associated with AF on the basis of a comprehensive overview of inflammation, oxidative and hemodynamic stress, hypertension, atherosclerosis, matrix metabolism, and other metabolic factors. We further selected 40 polymorphisms of these genes, most located in the promoter region, exons, or splice donor or acceptor sites of introns, that might be expected to result in changes in the function or expression of the encoded protein (data not shown).

Genotyping of polymorphisms. Venous blood (7 ml) was collected into tubes containing $50 \mathrm{mmol} / \mathrm{l}$ EDTA (disodium salt), and genomic DNA was isolated with a kit (Genomix; Talent, Trieste, Italy). Genotypes of the 40 polymorphisms were determined (G\&G Science, Fukushima, Japan) by a method that combines the polymerase chain reaction and sequence-specific oligonucleotide probes with analysis by suspension array technology (Luminex 100 flow cytometer, Luminex, Austin, TX). Primers, probes, and other conditions for genotyping are shown in Table I. Detailed methodology for genotyping was described previously (12).

Statistical analysis. Clinical data were compared between subjects with or without AF by the unpaired Student's t-test. Qualitative data were compared by the Chi-square test. Allele frequencies were estimated by the gene counting method, and the Chi-square test was used to identify departure from HardyWeinberg equilibrium. In the initial screen, the genotype distribution of each autosomal polymorphism was compared between subjects with or without AF by the Chi-square test ( $3 \times 2)$; for polymorphisms on the $\mathrm{X}$ chromosome, allele frequencies were compared by the Chi-square test $(2 \times 2)$. The false discovery rate (FDR) was calculated by the method of Benjamini and Hochberg (13). Calculation of the FDR is an approach to dealing with the problems associated with multiple comparisons and provides a measure of the expected proportion of false positives among data. The FDR threshold is determined from the observed P-value distribution and is adaptive to the signal level in data. The FDR differs from a P-value, and much higher FDRs than P-values can be tolerated. Initial screening of polymorphisms with the Chi-square test was followed by application of multivariable logistic regression analysis and a stepwise forward selection procedure for a more rigorous evaluation of association. The FDR was calculated at each step of the statistical analysis. In the initial screen (Chisquare test), the FDR was calculated from the distribution of 
Table II. Baseline characteristics of the study subjects $(n=1069)$.

\begin{tabular}{lccc}
\hline Characteristic & $\begin{array}{c}\text { Atrial fibrillation } \\
(\mathrm{n}=196)\end{array}$ & $\begin{array}{c}\text { Controls } \\
(\mathrm{n}=873)\end{array}$ & $\mathrm{P}$ \\
\hline Age (years) & $67.8 \pm 10.1$ & $60.3 \pm 10.8$ & 0.0001 \\
Sex (male/female) & $153 / 43$ & $302 / 571$ & $<0.0001$ \\
Body mass index $\left(\mathrm{kg} / \mathrm{m}^{2}\right)$ & $23.0 \pm 3.4$ & $24.0 \pm 3.3$ & $<0.0001$ \\
Smoking (\%) & 41.8 & 16.1 & $<0.0001$ \\
Hypertension (\%) & 44.4 & 29.2 & $<0.0001$ \\
Diabetes mellitus (\%) & 22.5 & 9.7 & $<0.0001$ \\
Hypercholesterolemia (\%) & 35.7 & 26.0 & $<0.0001$ \\
\hline
\end{tabular}

Data for age and body mass index are expressed as means $\pm \mathrm{SD}$. Smoker: smoking of $\geq 10$ cigarettes daily. Hypertension: systolic blood pressure of $\geq 140 \mathrm{mmHg}$ or diastolic blood pressure of $\geq 90 \mathrm{mmHg}$ (or both), or taking of antihypertensive medication. Diabetes mellitus: fasting plasma glucose concentration of $\geq 6.93 \mathrm{mmol} / 1(126 \mathrm{mg} / \mathrm{dl})$ or hemoglobin $A_{1 c}$ content of $\geq 6.5 \%$ (or both), or taking of antidiabetes medication. Hypercholesterolemia: serum total cholesterol concentration of $\geq 5.72 \mathrm{mmol} / 1(220 \mathrm{mg} / \mathrm{dl})$ or taking of lipid-lowering medication.

Table III. Polymorphisms related (FDR <0.05) to atrial fibrillation as revealed by the Chi-square test.

\begin{tabular}{llcc}
\hline Gene & \multicolumn{1}{c}{ Polymorphism } & P & FDR \\
\hline$I L 10$ & $-592 \mathrm{~A} \rightarrow \mathrm{C}$ & 0.0008 & 0.0320 \\
$I L 10$ & $-819 \mathrm{~T} \rightarrow \mathrm{C}$ & 0.0008 & 0.0160 \\
BCHE & $1615 \mathrm{G} \rightarrow \mathrm{A}($ Ala539Thr) & 0.0013 & 0.0173 \\
CETP & $1061 \mathrm{~A} \rightarrow \mathrm{G}$ (Ile405Val) & 0.0023 & 0.0230 \\
SLC26A8 & $\mathrm{A} \rightarrow \mathrm{G}(\mathrm{Ile} 639 \mathrm{Val})$ & 0.0023 & 0.0184 \\
MMP2 & $-1306 \mathrm{C} \rightarrow \mathrm{T}$ & 0.0072 & 0.0480 \\
TNF & $-238 \mathrm{G} \rightarrow \mathrm{A}$ & 0.0076 & 0.0434 \\
\hline
\end{tabular}

FDR, false discovery rate.

P-values for the 40 polymorphisms. Polymorphisms with an FDR of $<0.05$ were further examined by multivariable logistic regression analysis with adjustment for covariates, with AF as a dependent variable and independent variables including age, $\operatorname{sex}(0=$ woman, $1=$ man $)$, body mass index $(\mathrm{BMI})$, smoking status $(0=$ nonsmoker, $1=$ smoker $)$, metabolic variables $(0=$ no history of hypertension, diabetes mellitus, or hypercholesterolemia; 1 = positive history), and genotype of each polymorphism. Each genotype was assessed according to dominant $(0=$ wild-type homozygote, $1=$ heterozygote $=$ variant homozygote $)$, recessive $(0=$ wild-type homozygote $=$ heterozygote, $1=$ variant homozygote $)$, and additive $[(0,0)=$ wild-type homozygote, $(1,0)=$ heterozygote,$(0,1)=$ variant homozygote] genetic models, and the P-value, odds ratio, and $95 \%$ confidence interval were calculated. The additive genetic models each comprised two groups: heterozygotes versus wild-type homozygotes for the additive 1 model, and variant homozygotes versus wild-type homozygotes for the additive
Table IV. Genotype distributions (percent) of polymorphisms related to atrial fibrillation.

\begin{tabular}{|c|c|c|c|}
\hline Gene & Polymorphism & $\begin{array}{l}\text { Atrial fibrillation } \\
\qquad(\mathrm{n}=196)\end{array}$ & $\begin{array}{l}\text { Controls } \\
(\mathrm{n}=873)\end{array}$ \\
\hline \multirow[t]{4}{*}{ IL10 } & $-592 \mathrm{~A} \rightarrow \mathrm{C}$ & & \\
\hline & $A A$ & 48.5 & 41.6 \\
\hline & $A C$ & 46.9 & 45.3 \\
\hline & $C C$ & 4.6 & 13.2 \\
\hline \multirow[t]{4}{*}{ IL10 } & $-819 \mathrm{~T} \rightarrow \mathrm{C}$ & & \\
\hline & $T T$ & 48.5 & 41.7 \\
\hline & $T C$ & 46.9 & 45.1 \\
\hline & $C C$ & 4.6 & 13.2 \\
\hline \multirow[t]{4}{*}{ BCHE } & $1615 \mathrm{G} \rightarrow \mathrm{A}(\mathrm{Ala539Thr})$ & & \\
\hline & $G G$ & 67.4 & 73.1 \\
\hline & $G A$ & 26.0 & 24.9 \\
\hline & $A A$ & 6.6 & 2.0 \\
\hline \multirow[t]{4}{*}{ CETP } & $1061 \mathrm{~A} \rightarrow \mathrm{G}(\mathrm{Ile} 405 \mathrm{Val})$ & & \\
\hline & $A A$ & 22.4 & 24.1 \\
\hline & $A G$ & 58.2 & 45.8 \\
\hline & $G G$ & 19.4 & 30.1 \\
\hline \multirow[t]{4}{*}{ SLC26A8 } & $\mathrm{A} \rightarrow \mathrm{G}(\mathrm{Ile} 639 \mathrm{Val})$ & & \\
\hline & $A A$ & 47.5 & 52.1 \\
\hline & $A G$ & 49.5 & 39.4 \\
\hline & $G G$ & 3.0 & 8.5 \\
\hline \multirow[t]{4}{*}{$M M P 2$} & $-1306 \mathrm{C} \rightarrow \mathrm{T}$ & & \\
\hline & $C C$ & 76.0 & 84.7 \\
\hline & $C T$ & 22.5 & 14.9 \\
\hline & $T T$ & 1.5 & 0.4 \\
\hline \multirow[t]{4}{*}{$T N F$} & $-238 \mathrm{G} \rightarrow \mathrm{A}$ & & \\
\hline & $G G$ & 99.0 & 95.4 \\
\hline & $G A$ & 1.0 & 4.6 \\
\hline & $A A$ & 0.0 & 0.0 \\
\hline
\end{tabular}

2 model. We also performed a stepwise forward selection procedure to examine the effects of genotypes as well as of other covariates on AF. Given the multiple comparisons of genotypes with AF, we adopted the criterion of FDR $<0.05$ for significant association at each step of the statistical analysis. For other clinical background data, a P-value of $<0.05$ was considered statistically significant. Statistical significance was examined by two-sided tests, which were performed with JMP version 5.1 software (SAS Institute, Cary, NC).

\section{Results}

The baseline characteristics of the study subjects are shown in Table II. Age, the frequency of men, and the prevalence of smoking, hypertension, diabetes mellitus, and hypercholesterolemia were greater, whereas BMI was smaller, in subjects with AF than in controls. Evaluation of genotype distributions or allele frequencies by the Chi-square test 
Table V. Multivariable logistic regression analysis of polymorphisms related to atrial fibrillation with adjustment for age, sex, $\mathrm{BMI}$, and the prevalence of smoking, hypertension, diabetes mellitus, and hypercholesterolemia.

\begin{tabular}{|c|c|c|c|c|c|c|}
\hline \multirow[b]{2}{*}{ Gene } & \multirow[b]{2}{*}{ Polymorphism } & \multicolumn{3}{|c|}{ Dominant } & \multicolumn{2}{|c|}{ Recessive } \\
\hline & & $\mathrm{P}(\mathrm{FDR})$ & \multicolumn{2}{|c|}{ OR $(95 \% \mathrm{CI})$} & $\mathrm{P}(\mathrm{FDR})$ & OR $(95 \% \mathrm{CI})$ \\
\hline IL10 & $-592 A \rightarrow C$ & $0.1826(0.2638)$ & & & $0.0039(0.0338)$ & $0.33(0.15-0.67)$ \\
\hline ILIO & $-819 \mathrm{~T} \rightarrow \mathrm{C}$ & $0.1868(0.2556)$ & & & $0.0039(0.0254)$ & $0.33(0.15-0.67)$ \\
\hline BCHE & 1615G $\rightarrow$ A (Ala539Thr $)$ & $0.0466(0.0808)$ & \multicolumn{2}{|c|}{$1.48(1.00-2.18)$} & $0.0129(0.0335)$ & $3.27(1.28-8.34)$ \\
\hline CETP & $1061 \mathrm{~A} \rightarrow \mathrm{G}(\mathrm{Ile} 405 \mathrm{Val})$ & $0.9336(0.9336)$ & & & $0.0294(0.0588)$ & $0.62(0.40-0.95)$ \\
\hline SLC26A8 & $\mathrm{A} \rightarrow \mathrm{G}(\mathrm{Ile} 639 \mathrm{Val})$ & $0.4542(0.5134)$ & & & $0.0342(0.0635)$ & $0.38(0.14-0.87)$ \\
\hline$M M P 2$ & $-1306 \mathrm{C} \rightarrow \mathrm{T}$ & $0.0042(0.0218)$ & 1.9 & & $0.0176(0.0381)$ & $7.26(1.27-37.49)$ \\
\hline \multirow[t]{2}{*}{$T N F$} & $-238 \mathrm{G} \rightarrow \mathrm{A}$ & $0.0060(0.0223)$ & 0.1 & & & \\
\hline & \multicolumn{3}{|c|}{ Additive 1} & \multicolumn{3}{|c|}{ Additive 2} \\
\hline Gene & $\mathrm{P}(\mathrm{FDR})$ & \multicolumn{2}{|c|}{ OR $(95 \% \mathrm{CI})$} & \multicolumn{2}{|c|}{$\mathrm{P}(\mathrm{FDR})$} & OR $(95 \% \mathrm{CI})$ \\
\hline ILIO & $0.6655(0.7210)$ & & & \multicolumn{2}{|c|}{$0.0037(0.0962)$} & $0.32(0.14-0.66)$ \\
\hline IL10 & $0.0037(0.0481)$ & & & \multicolumn{2}{|c|}{$0.0037(0.0481)$} & $0.32(0.14-0.66)$ \\
\hline BCHE & $0.1974(0.2566)$ & & & \multicolumn{2}{|c|}{$0.0090(0.0293)$} & $3.50(1.36-9.00)$ \\
\hline CETP & $0.4085(0.4828)$ & & & \multicolumn{2}{|c|}{$0.2020(0.2501)$} & \\
\hline$S L C 26 A 8$ & $0.1641(0.2510)$ & & & \multicolumn{2}{|c|}{$0.0686(0.1115)$} & \\
\hline$M M P 2$ & $0.0132(0.0312)$ & \multicolumn{2}{|c|}{$1.78(1.12-2.79)$} & \multicolumn{2}{|c|}{$0.0126(0.0364)$} & $8.07(1.41-41.80)$ \\
\hline$T N F$ & $0.0060(0.0260)$ & \multicolumn{2}{|c|}{$0.12(0.02-0.44)$} & & & \\
\hline
\end{tabular}

FDR, false discovery rate; OR, odds ratio; CI, confidence interval. FDR values of $<0.05$ are shown in bold.

Table VI. Genotypes and other characteristics associated with atrial fibrillation as determined by a stepwise forward selection procedure.

\begin{tabular}{lccr}
\hline Characteristic & $R^{2}$ & $\mathrm{P}$ & FDR \\
\hline Sex & 0.1237 & $<0.0001$ & $<0.0001$ \\
Age & 0.0588 & $<0.0001$ & $<0.0001$ \\
Hypercholesterolemia & 0.0163 & $<0.0001$ & $<0.0001$ \\
IL10 (-592 A $\rightarrow \mathrm{C}$, recessive) & 0.0114 & 0.0006 & 0.0021 \\
Body mass index & 0.0100 & 0.0014 & 0.0039 \\
MMP2 (-1306C $\rightarrow \mathrm{T}$, dominant) & 0.0098 & 0.0016 & 0.0037 \\
Diabetes mellitus & 0.0054 & 0.0189 & 0.0378 \\
\hline
\end{tabular}

$R^{2}$, contribution rate; FDR, false discovery rate.

revealed that seven polymorphisms were related (FDR $<0.05$ ) to the prevalence of AF (Table III). The genotype distributions of these polymorphisms among subjects with AF and controls are shown in Table IV. The genotype distributions of these polymorphisms among control individuals were in HardyWeinberg equilibrium.
The seven polymorphisms related to AF by the Chi-square test were further examined by multivariate logistic regression analysis with adjustment for age, sex, BMI, and the prevalence of smoking, hypertension, diabetes mellitus, and hypercholesterolemia (Table V). The analysis revealed that the $-592 \mathrm{~A} \rightarrow \mathrm{C}$ and $-819 \mathrm{~T} \rightarrow \mathrm{C}$ polymorphisms of the interleukin 10 gene (IL10; recessive model and both recessive and additive 2 models, respectively), the $1615 \mathrm{G} \rightarrow \mathrm{A}$ (Ala539Thr) polymorphism of the butyrylcholinesterase gene $(B C H E$; recessive and additive 2 models), the $-1306 \mathrm{C} \rightarrow \mathrm{T}$ polymorphism of the matrix metalloproteinase 2 gene $(M M P 2$; dominant, recessive, and additive 1 and 2 models), and the $-238 \mathrm{G} \rightarrow \mathrm{A}$ polymorphism of the tumor necrosis factor gene (TNF; dominant and additive 1 models) were significantly (FDR $<0.05$ ) associated with the prevalence of AF. The $A$ allele of the $1615 \mathrm{G} \rightarrow \mathrm{A}$ polymorphism of $B C H E$ and the $T$ allele of the $-1306 \mathrm{C} \rightarrow \mathrm{T}$ polymorphism of $M M P 2$ were risk factors for $\mathrm{AF}$, whereas the $\mathrm{C}$ alleles of the $-592 \mathrm{~A} \rightarrow \mathrm{C}$ and $-819 \mathrm{~T} \rightarrow \mathrm{C}$ polymorphisms of IL1O and the $A$ allele of the $-238 \mathrm{G} \rightarrow \mathrm{A}$ polymorphism of $T N F$ were protective against this condition.

Finally, we performed a stepwise forward selection procedure to examine the effects of genotypes for the identified genes, age, sex, BMI, and the prevalence of smoking, hypertension, diabetes mellitus, and hypercholesterolemia on AF (Table VI). Each genotype was examined according to dominant or recessive models on the basis of statistical 
significance in the multivariate logistic regression analysis. In descending order of statistical significance, sex, age, hypercholesterolemia, ILI0 genotype $(-592 \mathrm{~A} \rightarrow \mathrm{C}$, recessive model), BMI, MMP2 genotype (-1306C $\rightarrow$ T, dominant model), and diabetes mellitus significantly $($ FDR $<0.05)$ and independently affected the prevalence of AF.

\section{Discussion}

Several genetic variants have been found to confer predisposition to AF, either by altering atrial electrophysiological properties or by contributing to a structural background susceptible to arrhythmia $(10,14,15)$. Herein we showed that the $T$ allele of the $-1306 \mathrm{C} \rightarrow \mathrm{T}$ polymorphism of $M M P 2$ is a risk factor for $\mathrm{AF}$, whereas the $\mathrm{C}$ allele of the $-592 \mathrm{~A} \rightarrow \mathrm{C}$ polymorphism of ILIO is protective against this condition. Our results thus implicate $M M P 2$ and $I L 10$ as candidate loci for genetic susceptibility to AF.

Electrical remodeling manifested by changes in transmembrane ionic currents and shortening of the atrial effective refractory period promotes the persistence of AF (16-19). An underlying structural remodeling might occur before, during, or after electrical remodeling and plays a pivotal role in progression of sustained AF (16). Contractile remodeling, manifested by a decrease in atrial contractility, occurs before structural remodeling such as the development of fibrosis and atrial dilation (20).

The notion that inflammation contributes to at least some types of AF is supported by genetic studies (21), the frequent occurrence of AF after cardiac surgery (22), and an association of AF with pericarditis (23). Inflammatory stimuli may lead to structural remodeling of atria that promotes progression and persistence of AF. Marked inflammatory infiltrates, myocyte necrosis, and fibrosis have been demonstrated in atrial biopsies of patients with lone AF (24). An increase in the plasma concentration of C-reactive protein observed in $\mathrm{AF}$ patients may reflect an inflammatory process that promotes the persistence of this condition (25). A population-based study also showed that the plasma concentration of C-reactive protein was significantly greater in patients with persistent lone AF than in individuals in normal sinus rhythm (26). These observations suggest that inflammatory changes may contribute to atrial structural remodeling and increase the propensity for AF persistence.

IL10 is a major anti-inflammatory cytokine that plays an important role in regulation of the immune system. It deactivates the inflammatory response mediated by macrophages and lymphocytes and inhibits the production of proinflammatory cytokines (27-31). An increased production of IL10 might thus result in better control of inflammatory responses induced by chronic vessel damage and reduce the risk of atherogenic complications (32). A previous study of the $-592 \mathrm{~A} \rightarrow \mathrm{C}$ polymorphism of $I L 10$ showed that the circulating level of IL10 was significantly higher in individuals with the $C C$ genotype than in those with the $A A$ genotype (33). The $A$ allele of this polymorphism is associated with reduced IL10 production by monocytes and macrophages compared with the $C$ allele, suggesting that the $-592 \mathrm{~A} \rightarrow \mathrm{C}$ polymorphism may affect the expression of $I L 10(34,35)$. The precise mechanisms by which genetic variants of ILIO might modulate atrial electrophysiological properties or the structural background conferring susceptibility to AF remain unknown. However, the results of our study suggest that the association of the $-592 \mathrm{~A} \rightarrow \mathrm{C}$ polymorphism of ILIO with the prevalence of AF may be attributable to anti-inflammatory effects of IL10 on atrial tissue.

Members of the matrix metalloproteinase (MMP) family of proteolytic enzymes mediate turnover of extracellular matrix components and are inhibited by tissue inhibitors of metalloproteinases (TIMPs) $(36,37)$. MMPs play an important role in pathological myocardial remodeling $(38,39)$. MMP2 (gelatinase) possesses the ability to degrade several interstitial proteins including basement membrane components such as type IV collagen (40). Mechanical stretch, a hallmark of arterial hypertension that leads to vessel wall remodeling and induces formation of reactive oxygen species by $\mathrm{NAD}(\mathrm{P}) \mathrm{H}$ oxidase, increases the expression and activity of MMPs, and reactive oxygen species contribute to vascular remodeling associated with arterial hypertension through MMP activation (41). Given that the extracellular matrix not only provides a supportive scaffold for myocytes and maintains the structural integrity of the heart but also cooperates with myocytes in activation conduction, changes in extracellular matrix components in the atrium have been considered likely to contribute to the development of sustained AF $(42,43)$. Remodeling of the atrial extracellular matrix, manifested by selective downregulation of TIMP2 expression and up-regulation of $M M P 2$ expression, has been associated with the development of sustained AF (43). The markedly increased expression of $M M P 2$ in the atria of patients with AF thus suggests the importance of this enzyme not only in extracellular matrix remodeling but also in the development of atrial dilation during progression of $\mathrm{AF}(43,44)$. In this study we showed that the $-1306 \mathrm{C} \rightarrow \mathrm{T}$ polymorphism of $M M P 2$ is associated with $\mathrm{AF}$, with the $T$ allele representing a risk factor for this condition. To clarify the effect of the $-1306 \mathrm{C} \rightarrow \mathrm{T}$ polymorphism on the expression of MMP2, we measured the serum activity of MMP2 in 46 individuals. There was no significant relation between this polymorphism and the enzyme activity (data not shown). The functional relevance of the $-1306 \mathrm{C} \rightarrow \mathrm{T}$ poly-morphism of $M M P 2$ to the etiology of AF thus remains to be elucidated.

Although we have provided evidence for a genetic basis of predisposition to AF, there are some limitations of our study: i) Measurements of parameters of structural remodeling in atria, such as left atrial size, were not performed in AF patients or control subjects. ii) Given the multiple comparisons of genotypes with AF, we adopted a level of FDR $<0.05$ for association. It is not possible, however, to exclude completely potential statistical errors such as false positives. iii) It is also possible that the $-1306 \mathrm{C} \rightarrow \mathrm{T}$ polymorphism of $M M P 2$ and the $-592 \mathrm{~A} \rightarrow \mathrm{C}$ polymorphism of IL1O are in linkage disequilibrium with polymorphisms in the same or nearby genes that are actually responsible for the development of AF. (iv) The functional relevance of the association of the $-1306 \mathrm{C} \rightarrow \mathrm{T}$ polymorphism of $M M P 2$ or the $-592 \mathrm{~A} \rightarrow \mathrm{C}$ polymorphism of $I L 10$ with $\mathrm{AF}$ remains to be determined.

In conclusion, our present results suggest that genetic variants of $M M P 2$ and $I L 10$ may be a risk factor for or protective factor against AF, respectively, in the Japanese 
population. Determination of genotypes for these polymorphisms may prove informative for assessment of the genetic component of AF and may contribute to the personalized prevention of this condition.

\section{Acknowledgements}

This study was supported in part by a Grant-in-Aid for Scientific Research from the Ministry of Education, Culture, Sports, Science, and Technology of Japan (no. 15209021, to Y.Y.) as well as by a grant from the Gifu Prefectural Science and Technology Promotion Center (Y.Y.). In addition to the authors, the following investigators participated in the study: Y. Matsuno and M. Tomita at Gifu Prefectural Gifu Hospital, Gifu, and A. Yoneyama and S. Suzuki at Gifu Prefectural Tajimi Hospital, Tajimi. We also thank the nursing and laboratory staff at the participating hospitals for their contributions.

\section{References}

1. Thom T, Haase N, Rosamond W, et al: Heart disease and stroke statistics-2006 update: a report from the American Heart Association Statistics Committee and Stroke Statistics Subcommittee. Circulation 113: E85-E151, 2006.

2. Wiesfeld AC, Hemels ME, Van Tintelen JP, Van den Berg MP, Van Veldhuisen DJ and Van Gelder IC: Genetic aspects of atrial fibrillation. Cardiovasc Res 67: 414-418, 2005.

3. Brugada R, Tapscott T, Czernuszewicz GZ, et al: Identification of a genetic locus for familial atrial fibrillation. N Engl J Med 336: 905-911, 1997.

4. Darbar D, Herron KJ, Ballew JD, et al: Familial atrial fibrillation is a genetically heterogeneous disorder. J Am Coll Cardiol 41: 2185-2192, 2003.

5. Kopecky SL, Gersh BJ, McGoon MD, et al: The natural history of lone atrial fibrillation. A population-based study over three decades. N Engl J Med 317: 669-674, 1987.

6. Ellinor PT, Shin JT, Moore RK, Yoerger DM and MacRae CA: Locus for atrial fibrillation maps to chromosome 6q14-16. Circulation 107: 2880-2883, 2003.

7. Oberti C, Wang L, Li L, et al: Genome-wide linkage scan identifies a novel genetic locus on chromosome $5 \mathrm{p} 13$ for neonatal atrial fibrillation associated with sudden death and variable cardiomyopathy. Circulation 110: 3753-3759, 2004.

8. Lai LP, Su MJ, Yeh HM, et al: Association of the human minK gene $38 \mathrm{G}$ allele with atrial fibrillation: evidence of possible genetic control on the pathogenesis of atrial fibrillation. Am Heart J 144: 485-490, 2002.

9. Ravn LS, Hofman-Bang J, Dixen U, et al: Relation of $97 \mathrm{~T}$ polymorphism in KCNE5 to risk of atrial fibrillation. Am J Cardiol 96: 405-407, 2005.

10. Firouzi M, Ramanna H, Kok B, et al: Association of human connexin 40 gene polymorphisms with atrial vulnerability as a risk factor for idiopathic atrial fibrillation. Circ Res 95: E29-E33, 2004.

11. Tsai CT, Lai LP, Lin JL, et al: Renin-angiotensin system gene polymorphisms and atrial fibrillation. Circulation 109: 1640-1646, 2004.

12. Itoh Y, Mizuki N, Shimada T, et al: High-throughput DNA typing of HLA-A, -B, -C, and -DRB1 loci by a PCR-SSOPLuminex method in the Japanese population. Immunogenetics 57: 717-729, 2005

13. Benjamini Y and Hochberg Y: Controlling the false discovery rate: a practical and powerful approach to multiple testing. J R Stat Soc Ser B 57: 289-300, 1995.

14. Gollob MH, Jones DL, Krahn AD, et al: Somatic mutations in the connexin 40 gene (GJA5) in atrial fibrillation. N Engl J Med 354: 2677-2688, 2006.

15. Schreieck J, Dostal S, von Beckerath N, et al: C825T polymorphism of the G-protein beta3 subunit gene and atrial fibrillation: association of the TT genotype with a reduced risk for atrial fibrillation. Am Heart J 148: 545-550, 2004.

16. Allessie M, Ausma J and Schotten U: Electrical, contractile and structural remodeling during atrial fibrillation. Cardiovasc Res 54: 230-246, 2002.
17. Brundel BJ, Henning RH, Kampinga HH, Van Gelder IC and Crijns HJ: Molecular mechanisms of remodeling in human atrial fibrillation. Cardiovasc Res 54: 315-324, 2002.

18. Kostin S, Klein G, Szalay Z, Hein S, Bauer EP and Schaper J: Structural correlate of atrial fibrillation in human patients. Cardiovasc Res 54: 361-379, 2002.

19. Ausma J, Dispersyn GD, Duimel H, et al: Changes in ultrastructural calcium distribution in goat atria during atrial fibrillation. J Mol Cell Cardiol 32: 355-364, 2000.

20. Allessie MA, Boyden PA, Camm AJ, et al: Pathophysiology and prevention of atrial fibrillation. Circulation 103: 769-777, 2001.

21. Gaudino M, Andreotti F, Zamparelli R, et al: The -174G/C interleukin-6 polymorphism influences postoperative interleukin-6 levels and postoperative atrial fibrillation. Is atrial fibrillation an inflammatory complication? Circulation 108 (Suppl 1): II195-II199, 2003.

22. Bruins P, te Velthuis H, Yazdanbakhsh AP, et al: Activation of the complement system during and after cardiopulmonary bypass surgery: postsurgery activation involves C-reactive protein and is associated with postoperative arrhythmia. Circulation 96: 3542-3548, 1997.

23. Spodick DH: Arrhythmias during acute pericarditis. A prospective study of 100 consecutive cases. JAMA 235: 39-41, 1976.

24. Frustaci A, Chimenti C, Bellocci F, Morgante E, Russo MA and Maseri A: Histological substrate of atrial biopsies in patients with lone atrial fibrillation. Circulation 96: 1180-1184, 1997.

25. Chung MK, Martin DO, Sprecher D, et al: C-reactive protein elevation in patients with atrial arrhythmias: inflammatory mechanisms and persistence of atrial fibrillation. Circulation 104: 2886-2891, 2001.

26. Aviles RJ, Martin DO, Apperson-Hansen C, et al: Inflammation as a risk factor for atrial fibrillation. Circulation 108: 3006-3010, 2003.

27. Moore KW, de Waal Malefyt R, Coffman RL and O'Garra A: Interleukin-10 and the interleukin-10 receptor. Annu Rev Immunol 19: 683-765, 2001.

28. Fiorentino DF, Zlotnik A, Mosmann TR, Howard M and O'Garra A: IL-10 inhibits cytokine production by activated macrophages. J Immunol 147: 3815-3822, 1991.

29. Schottelius AJ, Mayo MW, Sartor RB and Baldwin AS Jr: Interleukin-10 signaling blocks inhibitor of kappaB kinase activity and nuclear factor kappaB DNA binding. J Biol Chem 274: 31868-31874, 1999.

30. Donnelly RP, Dickensheets H and Finbloom DS: The interleukin-10 signal transduction pathway and regulation of gene expression in mononuclear phagocytes. J Interferon Cytokine Res 19: 563-573, 1999.

31. de Waal Malefyt R, Abrams J, Bennett B, Figdor CG and de Vries JE: Interleukin 10 (IL-10) inhibits cytokine synthesis by human monocytes: an autoregulatory role of IL-10 produced by monocytes. J Exp Med 174: 1209-1220, 1991.

32. Terkeltaub RA: IL-10: an 'immunologic scalpel' for atherosclerosis? Arterioscler Thromb Vasc Biol 19: 2823-2825, 1999.

33. Scarpelli D, Cardellini M, Andreozzi F, et al: Variants of the interleukin-10 promoter gene are associated with obesity and insulin resistance but not type 2 diabetes in Caucasian Italian subjects. Diabetes 55: 1529-1533, 2006.

34. Rosenwasser LJ and Borish L: Genetics of atopy and asthma: the rationale behind promoter-based candidate gene studies (IL-4 and IL-10). Am J Respir Crit Care Med 156: S152-S155, 1997.

35. Summers AM, Summers CW, Drucker DB, Hajeer AH, Barson A and Hutchinson IV: Association of IL-10 genotype with sudden infant death syndrome. Hum Immunol 61: 1270-1273, 2000.

36. Li YY, Feldman AM, Sun Y and McTiernan CF: Differential expression of tissue inhibitors of metalloproteinases in the failing human heart. Circulation 98: 1728-1734, 1998.

37. Thomas CV, Coker ML, Zellner JL, Handy JR, Crumbley AJ III and Spinale FG: Increased matrix metalloproteinase activity and selective upregulation in LV myocardium from patients with end-stage dilated cardiomyopathy. Circulation 97: 1708-1715, 1998.

38. Spinale FG: Matrix metalloproteinase gene polymorphisms in heart failure: new pieces to the myocardial matrix puzzle. Eur Heart J 25: 631-633, 2004.

39. Hoit BD: Matrix metalloproteinases and atrial structural remodeling. J Am Coll Cardiol 42: 345-347, 2003. 
40. Spinale FG, Coker ML, Heung LJ, et al: A matrix metalloproteinase induction/activation system exists in the human left ventricular myocardium and is upregulated in heart failure. Circulation 102: 1944-1949, 2000.

41. Grote K, Flach I, Luchtefeld M, et al: Mechanical stretch enhances mRNA expression and proenzyme release of matrix metalloproteinase-2 (MMP-2) via NAD(P)H oxidase-derived reactive oxygen species. Circ Res 92: E80-E86, 2003.
42. Sackner-Bernstein JD: The myocardial matrix and the development and progression of ventricular remodeling. Curr Cardiol Rep 2: 112-119, 2000.

43. Xu J, Cui G, Esmailian F, et al: Atrial extracellular matrix remodeling and the maintenance of atrial fibrillation. Circulation 109: 363-368, 2004

44. Nakano Y, Niida S, Dote K, et al: Matrix metalloproteinase-9 contributes to human atrial remodeling during atrial fibrillation. J Am Coll Cardiol 43: 818-825, 2004. 